\title{
Study of Blunt Abdominal Injuries in A Tertiary Care Hospital - A Prospective Study
}

\author{
B. Sivakumar ${ }^{1}$, N. Salem Abdul Kuthush ${ }^{2}$ \\ ${ }^{1}$ Assistant Professor, Department of General Surgery, Pudukottai Government Medical College and Hospital, Tamilnadu, \\ ${ }^{2}$ Assistant Professor, Department of General Surgery, Pudukottai Government Medical College and Hospital, Tamilnadu, \\ India
}

Corresponding author: Dr. N. Salem Abdul Kuthush, Assistant Professor, Department of General Surgery, Pudukottai Government Medical College and Hospital, Tamilnadu, India

DOI: http://dx.doi.org/10.21276/ijcmsr.2019.4.2.40

How to cite this article: B. Sivakumar, N. Salem Abdul Kuthush. Study of blunt abdominal injuries in a tertiary care hospital - a prospective study. International Journal of Contemporary Medicine Surgery and Radiology. 2019;4(2):B181-B184.

\section{A B S T R A C T}

Introduction: Blunt injury to the abdomen is encountered more often these days due to rapid industrialization and the presence of more number of vehicles, thus leading to more number of accidents. Blunt injury abdomen is seen in increasing frequency in emergency rooms and therefore, the early diagnosis and treatment of the patient is very important. Current research aimed to study the clinical presentation, management and complications associated with blunt abdominal injuries.

Material and Methods: This Prospective study was conducted in a tertiary care hospital from February 2018 to December 2018. 100 patients with blunt abdominal injuries who reported to the emergency department were selected for the study. Retroperitoneal injuries, associated chest/ head/ musculoskeletal injuries needing emergency surgical intervention patients were excluded.

Results: 100 patients with blunt abdominal injuries, a male predominance (84 patients) was noticed. About $54 \%$ of the patients were between 25 and 35 years of age. RTA (62\%) was the commonest mode of injury. The abdominal organ most affected was the liver (26\%). The small intestine was affected in about $19 \%$ of the patients and the splenic injury was observed in 14\%. Amongst the 26 patients with liver injury 24 patients were treated conservatively and 2 patients needed surgery.

Conclusion: Trauma predominantly affects the male population in their most productive age and hence eventually poses an economic burden to the national economy as well as on families. Initial resuscitation with correct clinical and radiological assessment and timely management is the most important step in the management of the blunt abdominal injury.

Keywords: Blunt Abdominal Trauma, Trauma, Spleen, Early Diagnosis, Resuscitation

\section{INTRODUCTION}

Abdominal injury due to a blunt force is a common presentation in the emergency room and is the leading cause of mortality and morbidity in children and in adults. ${ }^{1}$ The primary reason for a blunt abdominal injury is road traffic accident. Other causes may be fall from a height, sports injuries, bicycle injury, industrial injuries, assaults and abdominal injury from child abuse., ${ }^{2,3}$ Surgery is required in about $25 \%$ of the civilians who suffer abdominal injury. ${ }^{4}$ The abdomen is the third most common region to get injured and the injury can be either blunt or penetrating. Blunt injuries are often missed as the clinical signs are less obvious. Penetrating wounds can be classified as stab wounds and gunshot wounds and require different methods of management. ${ }^{5}$ Blunt abdominal injuries can damage the liver, spleen, pancreas, bowel and intestines and may result in bleeding or contusions. The risk factors for mortality from abdominal injury should be identified to minimize them.
Some of the risk factors determining the mortality rates are sex, the interval between the time of injury and surgery, shock and related cranial injury. ${ }^{6}$

The presentation of a blunt abdominal injury is not straightforward which makes diagnosis difficult and timeconsuming. One must look for signs like lap belt marks, ecchymosis, abdominal distension, abnormal or absent bowel sounds and tenderness on palpation. Patients may also present with bleeding per rectum, unstable vitals and peritonitis. The abdomen may be rigid if peritonitis is present. ${ }^{7}$ The type of injury and its mechanism, alcohol use and the associated deaths at the scene should be taken into consideration in order that an injury is not missed.

Blunt trauma involves a direct blow (a kick), impact with an object (a fall onto bicycle handlebars), or a sudden decrease in speed (a fall from a height or a motor vehicle crash) where the spleen and liver are commonly injured; injury to the hollow organs are less likely. Penetrating injury is when an object breaks the skin (gunshot or a stabbing) and some 
may enter the abdominal cavity. Blunt injuries may cause rupture of the internal organs leading to blood collection inside the solid organs(liver) or in the wall of hollow organs like small intestine[hematomas] or may also lead to uncontained bleeding into the abdominal space which is called hemoperitoneum. Deaths from blunt injuries can be prevented if diagnosed and treated promptly. ${ }^{8}$ If a misdiagnosis is made the outcome will be worse and delayed treatment might lead to high morbidity and mortality., ${ }^{9}$

Current research aimed to study the clinical presentation, management and complications associated with blunt abdominal injuries.

\section{MATERIALS AND METHODS}

This Prospective study was conducted in a tertiary care hospital from February 2018 to December 2018. 100 patients with blunt abdominal injuries who reported to the emergency department were selected for the study.

Inclusion criteria: Age $>18$ years, all gastrointestinal tract injuries (stomach, small intestine, large intestine, liver, spleen, diaphragm, mesentery).

Exclusion criteria: Retroperitoneal injuries, Associated chest/ head/ musculoskeletal injuries needing emergency surgical intervention.

Clinical data regarding patient demographics, mechanism of injury, hemodynamic status on presentation was noted. Basic investigations like complete hemogram, serology, abdominal ultrasonography, chest X-ray and erect X-ray abdomen were performed in all the cases. The decision for operative or non-operative management depended on the outcome of the clinical examination, hemodynamic stability of the patient and the results of the investigations done. Patients selected for conservative management were placed on strict bed rest. They were also subjected to the serial clinical examination which included hourly pulse rate, blood pressure, respiratory rate and repeated examination of the abdomen and other systems. Appropriate investigations, such as the haemoglobin value, and ultrasound of the abdomen were repeated as and when necessary. Sometimes, in cases of liver and splenic injury, if the patient is haemodynamically stable, then the patient can be treated conservatively.

\section{RESULTS}

In this prospective study of 100 patients with blunt abdominal injuries, a male predominance ( 84 patients) was noticed. About $54 \%$ of the patients were between 25 and 35 years of age. The etiology of the injuries were mainly RTA (62\%) followed by assault or injuries with blunt objects (16\%) and fall from height (12\%). The abdominal organ most affected was the liver (26\%). The small intestine was affected in about $19 \%$ of the patients and the splenic injury was observed in $14 \%$. Kidney and retroperitoneal involvement were also seen. The diaphragm, urinary bladder and pancreas were least injured (table-1). Amongst the 26 patients with liver injury 24 patients were treated conservatively and 2 patients needed surgery. Patients with kidney, pancreas and retroperitoneal involvement did not need any surgery and

\begin{tabular}{|l|c|c|}
\hline & $\mathbf{N = 1 0 0}$ & $\mathbf{N} \%$ \\
\hline Males & 84 & $84 \%$ \\
Females & 16 & $16 \%$ \\
\hline incidence of 25 to 35 yrs age group & 54 & $54 \%$ \\
\hline Causes & & \\
RTA & 62 & $62 \%$ \\
Assault / injury with blunt objects & 16 & $16 \%$ \\
Fall from height & 12 & $12 \%$ \\
\hline Organs involved & & \\
Liver & 26 & $26 \%$ \\
Small intestine & 19 & $19 \%$ \\
Spleen & 14 & $14 \%$ \\
Retroperitoneum & 13 & $13 \%$ \\
Kidney & 12 & $12 \%$ \\
Large intestine & 6 & $6 \%$ \\
Mesentery & 4 & $4 \%$ \\
Diaphragm & 3 & $3 \%$ \\
Bladder & 2 & $2 \%$ \\
Pancreas & 1 & $1 \%$ \\
\hline \multicolumn{2}{|c|}{ Table-1: Incidence, causes and organs damaged in BAT } \\
\hline
\end{tabular}

\begin{tabular}{|l|c|c|c|}
\hline Organ & Total cases & Surgery & Conservative \\
\hline Liver & 26 & 2 & 24 \\
\hline Spleen & 14 & 8 & 6 \\
\hline Kidney & 12 & 0 & 12 \\
\hline Pancreas & 1 & 0 & 1 \\
\hline Retroperitoneum & 13 & 0 & 13 \\
\hline Hollow viscera & 29 & 29 & 0 \\
\hline Diaphragm & 3 & 3 & 0 \\
\hline Urinary bladder & 2 & 2 & 0 \\
\hline \multicolumn{4}{|r|}{ Table-2: Treatment adopted } \\
\hline
\end{tabular}

\begin{tabular}{|l|c|}
\hline Mortality & Total cases \\
\hline Shock & 2 \\
\hline Septicemia & 4 \\
\hline Renal failure & 2 \\
\hline Cardio/resp failure & 5 \\
\hline \multicolumn{2}{|c|}{ Table-3: Reasons for mortality and outcomes } \\
\hline
\end{tabular}

required only conservative therapy. In the 29 patients with hollow visceral organ involvement (like small intestine) all 29 of them needed immediate surgery to avoid mortality (table-2). This is due to the rich and profuse blood supply to the hollow visceral organs which if left untreated may result in excessive bleeding and death of the patient. A total of 19 deaths were reported in this study which indicates that fatality rates associated with blunt abdominal trauma are relatively high (table-3). The fatality could be associated with risk factors like delay in treatment, comorbidities, shock at the time of admission, haemodynamic instability, septicemia, renal failure or cardiorespiratory failure.

\section{DISCUSSION}

Motor vehicle collisions and other road traffic accidents are the common causes of abdominal trauma and can occur at any age. ${ }^{11}$ Seat belts can reduce head and chest injuries but pose a threat to the internal organs like pancreas and intestines. The organs may be displaced or compressed against the spine. Children are more vulnerable to seat belt injuries due to their 
soft abdominal regions. Handlebar strikes while cycling or at play are another threat to children. ${ }^{12}$ Sports injuries and fall from heights can injure the spleen and kidneys. Moreover children and teenage girls suffer abdominal trauma from child abuse and this stands as the second leading cause of death after brain injury. ${ }^{13}$ The reason why abdominal injuries are life-threatening is that the organs in the retroperitoneal space can bleed profusely and this space holds a good deal of blood which can go unnoticed for quite some time resulting in hypovolemic shock before the patient gets admitted to the emergency department. ${ }^{14}$

Solid organs like kidney and liver bleed profusely like the major blood vessels when cut or damaged and lead to shock very rapidly. Hollow organs like stomach and intestines can result in infections rather than shock if not treated appropriately due to the spillage of bowel contents into the peritoneal space. Septicemia and hypovolemic shock are the main reasons for mortality from blunt abdominal trauma. The size and location of the liver (right upper quadrant) make it more vulnerable and about $5 \%$ of the patients with abdominal trauma present with liver injury. ${ }^{15}$ The risk of serious shock is more with the liver due to its profuse blood supply and capacity. Lacerations, contusions and hematoma are common in the liver and it may even result in exsanguination (bleeding to death) which necessitates an emergency surgery. ${ }^{16}$ This study also shows a higher incidence of liver injury (26\%) with surgery being done in 2 patients.

The spleen is the major organ of massive bleeding due to blunt abdominal injuries and a ruptured spleen can be lifethreatening. Unless a major blood vessel such as the renal artery supplying organs like spleen, pancreas and kidney is damaged they do not pose a threat of immediate shock unlike liver. Fractures of the left lower rib can cause spleen lacerations. As the small intestine takes up a large part of the abdomen and it is likely to be damaged in abdominal injuries. Gas in the abdominal cavity as revealed in $\mathrm{CT}$ is a sign of bowel perforation. This must be differentiated with pneumomediastinum or pneumothorax which can also cause the intraabdominal air. Bowel perforations can complicate as abscess, septicemia, bowel obstruction or fistula formation and need immediate surgery. In this study out of the 29 patients with hollow visceral organ damage (stomach, small and large intestines) all 29 of them needed surgery.

The evaluation of any patient with trauma begins with A,B,C (airway, breathing and circulation). ${ }^{17}$ If the patient is hemodynamically stable, the CT scan can be performed to assess abdominal and pelvic injuries. USG or Extended Focussed Assessment with Sonography for Trauma (EFAST) can be performed in unstable patients. ${ }^{18}$ Peritoneal lavage is a controversial procedure that carries a high risk of false positive or false negative results. ${ }^{19}$ The emergency physician should look for lap belt marks, steering wheelshaped contusions, ecchymosis in the flanks and abdominal distension. Auscultatory bowel sounds and bruits may be present in diaphragmatic injury and indicate an underlying vascular disease. $^{20}$

Once the primary survey $(\mathrm{A}, \mathrm{B}, \mathrm{C})$ is clear, hypovolemic patients require fluid resuscitation. Immediate $\mathrm{O}$-ve blood transfusion can be done and later crossed and typed blood can be transfused. If the patient's clinical signs worsen immediate laparotomy is done. Conservative management depends on the extent of the injury and the hemodynamic stability of the patient. Hemorrhage control can be done by angiography assisted embolization and patients show a good prognosis. If the abdominal injury is misdiagnosed or not promptly treated on time the prognosis can be worse. The associated complications can be intra-abdominal sepsis, delayed splenic rupture, cardiorespiratory failure, shock and death. In this study 19 (19\%) deaths were recorded owing to many reasons which are relatively high. Mortality could be influenced by the presence of cranial injuries, comorbidities, the general health status of the patient, type and extent of the injury, the length between the time of injury and the time of admission and the presence of shock at the time of admission.

\section{CONCLUSION}

Prompt and early diagnosis is mandatory to control the morbidity and mortality rates. A relatively high mortality rate of $19 \%$ was observed which indicates the seriousness and immediate care to be exercised in the treatment of such injuries. Cases treated promptly showed a good prognosis.

\section{REFERENCES}

1. Garside G, Khan O, Mukhtar Z, Sinha C. Paediatric duodenal injury complicated by common bile duct rupture due to blunt trauma: a multispecialist approach. BMJ Case Rep. 2018;29(1):23-29.

2. Molinelli V, Iosca S, Duka E, De Marchi G, Lucchina N, Bracchi E, Carcano G, Novario R, Fugazzola C. Ability of specific and nonspecific signs of multidetector computed tomography (MDCT) in the diagnosis of blunt surgically important bowel and mesenteric injuries. Radiol Med. 2018;123(12):891-903.

3. Taghavi S, Askari R. StatPearls [Internet]. StatPearls Publishing; Treasure Island (FL): Jan 13, 2019. Liver Trauma.

4. Hemmila MR, Wahl WL. Management of the Injured Patient. In: Doherty GM, editor. Current Surgical Diagnosis and Treatment.McGraw-Hill Medical; 2008. pp. 227-8.

5. Investigation of blunt abdominal trauma. Jansen JO, Yule SR, Loudon MA BMJ. 2008;336(7650):938-42.

6. Predicting factors for mortality in the penetrating abdominal trauma. Aldemir M, Taçyildiz I, Girgin S Acta Chir Belg. 2004; 104(4):429-34.

7. So HF, Nabi H. Handlebar hernia - A rare complication from blunt trauma. Int J Surg Case Rep. 2018;49:118120.

8. Yeo A (2004). "Abdominal trauma". In Chih HN, Ooi LL. Acute Surgical Management. World Scientific Publishing Company. pp. 327-33. ISBN 978-981-238681-6. Retrieved 2008-06-21.

9. Jansen JO, Yule SR, Loudon MA. Investigation of blunt abdominal trauma. BMJ. 2008; 336 (7650): 938-42.

10. Visrutaratna $\mathrm{P}, \mathrm{Na}$-Chiangmai W. Computed tomography of blunt abdominal trauma in children. Singapore Med J. 49 (4): 352-8.

11. Hemmila MR, Wahl WL. Management of the Injured Patient. In Doherty GM. Current Surgical Diagnosis and Treatment. McGraw-Hill Medical. pp. 227-8. 
12. Bixby SD, Callahan MJ, Taylor GA. Imaging in pediatric blunt abdominal trauma. Semin Roentgenol. 2008; 43 (1): 72-82.

13. Lichtenstein R, Suggs AH (2006). "Child abuse/assault". In Olshaker JS, Jackson MC, Smock WS. Forensic Emergency Medicine: Mechanisms and Clinical Management (Board Review Series). Hagerstown, MD: Lippincott Williams \& Wilkins. pp. 157-9. ISBN 9780-7817-9274-5. Archived from the original on 201711-06. Retrieved 2008-06-21.

14. Blank-Reid C. A historical review of penetrating abdominal trauma. Crit Care Nurs Clin North Am. 2006; 18 (3): 387-401.

15. Fabian TC, Bee TK (2004;). Liver and biliary trauma. In Moore EJ, Feliciano DV, Mattox KL. Trauma. New York: McGraw-Hill, Medical Pub. Division. p. 637. ISBN 978-0-07-137069-1. Archived from the original on 2017-11-06. Retrieved 2008-06-21.

16. Visrutaratna $\mathrm{P}, \mathrm{Na}$-Chiangmai W. Computed tomography of blunt abdominal trauma in children. Singapore Med J. 2008;49 (4): 352-8.

17. Molinelli V, Iosca S, Duka E, De Marchi G, Lucchina N, Bracchi E, Carcano G, Novario R, Fugazzola C. Ability of specific and nonspecific signs of multidetector computed tomography (MDCT) in the diagnosis of blunt surgically important bowel and mesenteric injuries. Radiol Med. 2018;123(12):891-903.

18. Wortman JR, Uyeda JW, Fulwadhva UP, Sodickson AD. Dual-Energy CT for Abdominal and Pelvic Trauma. Radiographics. 2018; 3 8(2): 586-602. [PubMed] [Reference list]

19. Tsai R, Raptis D, Raptis C, Mellnick VM. Traumatic abdominal aortic injury: clinical considerations for the diagnostic radiologist. Abdom Radiol (NY). 2018;43(5):1084-1093.

20. Margari S, Garozzo Velloni F, Tonolini M, Colombo E, Artioli D, Allievi NE, Sammartano F, Chiara O, Vanzulli A. Emergency CT for assessment and management of blunt traumatic splenic injuries at a Level 1 Trauma Center: 13-year study. Emerg Radiol. 2018 May 12; [PubMed]

Source of Support: Nil; Conflict of Interest: None

Submitted: 11-04-2019; Accepted: 13-05-2019; Published online: 30-06-2019 